\title{
DEVELOPMENT OF A 15 T NB33 SN ACCELERATOR DiPOLE DEMONSTRATOR AT FERMILAB
}

\author{
I. Novitski, N. Andreev, E. Barzi, J. Carmichael, V. V. Kashikhin, D. Turrioni, M. Yu, and A. V. Zlobin
}

\begin{abstract}
A $100 \mathrm{TeV}$ scale Hadron Collider (HC) with a nominal operation field of at least $15 \mathrm{~T}$ is being considered for the post-LHC era, which requires using the $\mathrm{Nb}_{3} \mathrm{Sn}$ technology. Practical demonstration of this field level in an accelerator-quality magnet and substantial reduction of the magnet costs are important requirements for realization of such a machine. Fermilab has started the development of a $15 \mathrm{~T} \mathrm{Nb}_{3} \mathrm{Sn}$ dipole demonstrator for a $100 \mathrm{TeV}$ scale $\mathrm{HC}$. The magnet design is based on optimized 60-mm aperture 4-layer shell-type coils, graded between the inner and outer layers to maximize the performance and reduce the cost. The experience gained during the $\mathrm{Nb}_{3} \mathrm{Sn}$ magnet $R \& D$ is applied to various aspects of the magnet design. This paper describes the magnetic and structural designs and parameters of the $15 \mathrm{~T} \mathrm{Nb3Sn}$ dipole demonstrator and the steps towards its fabrication.
\end{abstract}

Index Terms - Dipole magnet, collider, magnetic field, mechanical structure, $\mathrm{Nb}_{3} \mathrm{Sn}$ superconductor, Rutherford cable.

\section{INTRODUCTION}

$\mathrm{H}$ ADRON COLLIDERS (HC) are the most powerful discovery tools in modern high energy physics. Interest in an $\mathrm{HC}$ with energy above the LHC reach has gained further momentum in the strategic plans recently developed in the U.S., Europe and China [1]-[3]. To build a $\sim 100 \mathrm{TeV}$ center of mass energy HC in a $\sim 100 \mathrm{~km}$ tunnel, dipoles with a nominal field of $\sim 15 \mathrm{~T}$ and $\sim 20 \%$ margin operating at $1.9 \mathrm{~K}$ or $4.5 \mathrm{~K}$ are needed. A nominal field of $\sim 15 \mathrm{~T}$ can be provided only by the $\mathrm{Nb}_{3} \mathrm{Sn}$ technology. A practical demonstration of this field level in acceleratorquality magnets and a substantial reduction of magnet costs are important requirements for the realization of such a machine.

The foremost challenges for $15 \mathrm{~T} \mathrm{Nb}_{3} \mathrm{Sn}$ magnets include considerably larger coil volume, higher Lorentz forces and larger stored energy than in present accelerator magnets. The coil width, necessary to achieve the $15 \mathrm{~T}$ field level, requires 4layer coil design [4]. The stronger forces produce higher stresses in the coil and in the mechanical structure and, thus, measures of stress control may be needed to keep stress and strain at an acceptable level for brittle $\mathrm{Nb}_{3} \mathrm{Sn}$ conductor. The large stored energy also leads to complications in the magnet quench protection.

Fermilab has started the development of a $15 \mathrm{~T} \mathrm{Nb}_{3} \mathrm{Sn}$ dipole demonstrator for a $100 \mathrm{TeV}$ scale $\mathrm{HC}$ based on the optimized "cos-theta" coil design [4], [5]. The experience gained at Fermilab during the $\mathrm{Nb}_{3} \mathrm{Sn}$ accelerator magnet R\&D for a Very Large Hadron Collider (VLHC) and the LHC upgrades [6], [7]

The work supported by Fermi Research Alliance, LLC, under contract No. DEAC02-07CH11359 with the U.S. Department of Energy. will be applied to all stages of the magnet design and fabrication. The main objectives of this magnet are demonstration of the $15 \mathrm{~T}$ field level in an aperture suitable for a future $\mathrm{HC}$ and study of the magnet quench performance and margins, quench protection and field quality. This paper describes the design concept and parameters of the $15 \mathrm{~T} \mathrm{Nb}_{3} \mathrm{Sn}$ dipole demonstrator developed at Fermilab. Magnetic and structural analyses as well as cable development and test results are also reported and discussed.

\section{MAGNET DESIGN AND PARAMETERS}

Five 4-layer graded coil cross-sections with $60-\mathrm{mm}$ aperture were designed using ROXIE code [8] based on two cables with $15 \mathrm{~mm}$ width and thicknesses as listed in Table I [4]. The cables use $1.0 \mathrm{~mm}$ and $0.7 \mathrm{~mm} \mathrm{Nb}_{3} \mathrm{Sn}$ strands with a nominal critical current density $J_{c}$ of $1500 \mathrm{~A} / \mathrm{mm}^{2}$ at $15 \mathrm{~T}$ and $4.2 \mathrm{~K}$, and a nominal $\mathrm{Cu} / \mathrm{SC}$ ratio of 1.13. Similar $\mathrm{Nb}_{3} \mathrm{Sn}$ cables had already been developed at Fermilab and used in earlier dipole models [9], [10].

TABLE I

DIMENSIONS OF REACTED BARE CABLES

\begin{tabular}{lccc}
\hline \hline Parameter & Units & Cable 1 & Cable 2 \\
\hline Number of strands & & 28 & 40 \\
Mid-thickness & $\mathrm{mm}$ & 1.870 & 1.319 \\
Width & $\mathrm{mm}$ & 15.10 & 15.10 \\
Keystone angle & degree & 0.805 & 0.805 \\
\hline \hline
\end{tabular}

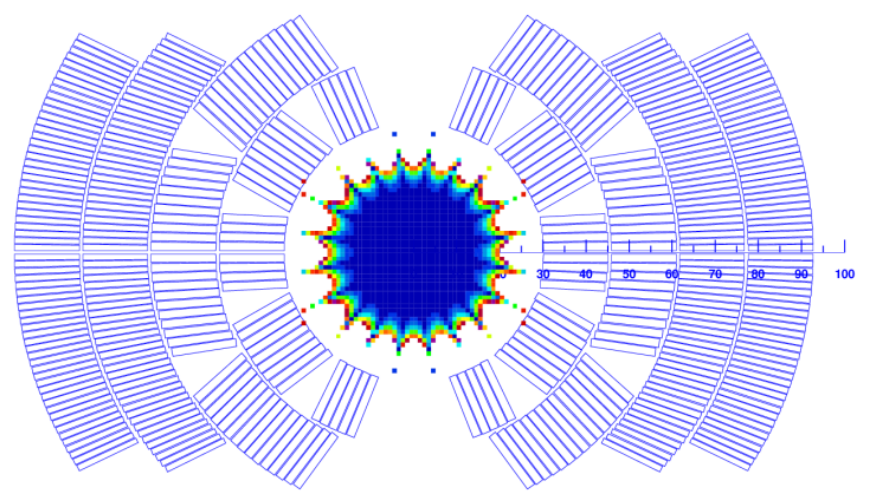

Fig. 1. Coil cross-section with field quality diagram in the coil aperture. The dark colored zone represents a field uniformity better than $2 \times 10^{-4}$.

Based on the design studies described in [4], a 4-layer 60-

All authors are with the Fermi National Accelerator Laboratory (Fermilab), Batavia, IL 60510 USA (e-mail: zlobin@fnal.gov). 
$\mathrm{mm}$ aperture graded coil with optimized number of turns was selected for the $15 \mathrm{~T}$ dipole demonstrator. The selected coil cross-section is shown in Fig. 1. The two innermost layers have five blocks separated by 3 wedges. The two outermost layers do not use wedges. The large field harmonics generated by the two outermost layers were compensated by optimizing the number of turns and the wedge size and position in the two innermost layers. The resulting good field quality area in the aperture is shown in Fig. 1 by the dark colored zone.

The mechanical structure of the $15 \mathrm{~T}$ dipole demonstrator has been significantly reworked with respect to the original one described in [5] to address the large stress and deformation values revealed by ANSYS analysis. The new cold-mass structure of the $15 \mathrm{~T}$ dipole demonstrator is shown in Fig. 2.

The 4-layer coil assembly is surrounded by a $2 \mathrm{~mm}$ stainless steel spacer and supported by a vertically split iron yoke locked by aluminum clamps. The yoke is surrounded by a $12 \mathrm{~mm}$ thick stainless steel skin. The I-shaped clamps interleave with the iron yoke laminations in the top and bottom sectors of the iron yoke, thus reducing the iron filling factor in these areas to $\sim 50 \%$.

The axial Lorentz forces on the coil ends are intercepted by two thick end plates connected by eight stainless steel tie rods running through the dedicated holes in the iron yoke. This new support structure is different from the original concept based on stainless steel C-clamps and a thick skin [5]. It provides better stress management, as explained in the following section.

The magnet cold-mass is $\sim 1 \mathrm{~m}$ long. The maximum cold mass transverse size is $\sim 610 \mathrm{~mm}$, which is limited by the inner diameter of the Fermilab test cryostat. Quench protection heaters composed of stainless steel strips are placed between the $2^{\text {nd }}$ and $3^{\text {rd }}$ coil layers and on the coil outer layer.

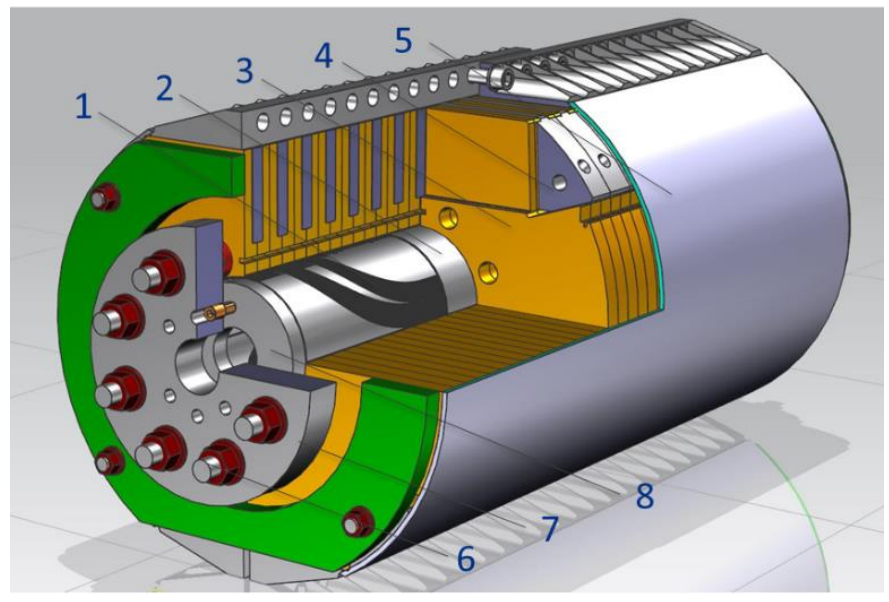

Fig. 2. Cold mass design of the $15 \mathrm{~T}$ dipole demonstrator: 1 - 4-layer $\mathrm{Nb}_{3} \mathrm{Sn}$ coil; 2 - coil-yoke stainless steel spacer; 3 - iron yoke laminations; 4 aluminum I-clamp; 5 - stainless steel bolted skin; 6 - axial tie rod; 7 - stainless steel end plate with instrumented bullets; 8 - pusher ring.

The calculated 2D design parameters of the $15 \mathrm{~T}$ dipole demonstrator are summarized in Table II. The field distribution diagrams in the coil and iron yoke are shown in Fig. 3. An iron filling factor of $50 \%$ in the area of the I-clamps was considered in the calculations. The maximum design bore field at $4.2 \mathrm{~K}$ is
15.6 T. Reducing the coil temperature to $1.9 \mathrm{~K}$ allows increasing the maximum bore field by $\sim 10 \%$ with respect to the values shown in Table II.

TABLE II

MAGNET DESIGN PARAMETERS AT $4.2 \mathrm{~K}$.

\begin{tabular}{lcc}
\hline \hline Parameter & Unit & Value \\
\hline Bore field at short sample limit & $\mathrm{T}$ & 15.61 \\
Peak field at short sample limit & $\mathrm{T}$ & 16.25 \\
Current at short sample limit, $\mathrm{I}_{\mathrm{c}}$ & $\mathrm{kA}$ & 11.34 \\
Inductance at $\mathrm{I}_{\mathrm{c}}$ & $\mathrm{mH} / \mathrm{m}$ & 25.61 \\
Stored energy at $\mathrm{I}_{\mathrm{c}}$ & $\mathrm{MJ} / \mathrm{m}$ & 1.65 \\
Horizontal Lorentz force per quadrant at $\mathrm{I}_{\mathrm{c}}$ & $\mathrm{MN} / \mathrm{m}$ & 7.36 \\
Vertical Lorentz force per quadrant at $\mathrm{I}_{\mathrm{c}}$ & $\mathrm{MN} / \mathrm{m}$ & -4.50 \\
\hline \hline
\end{tabular}
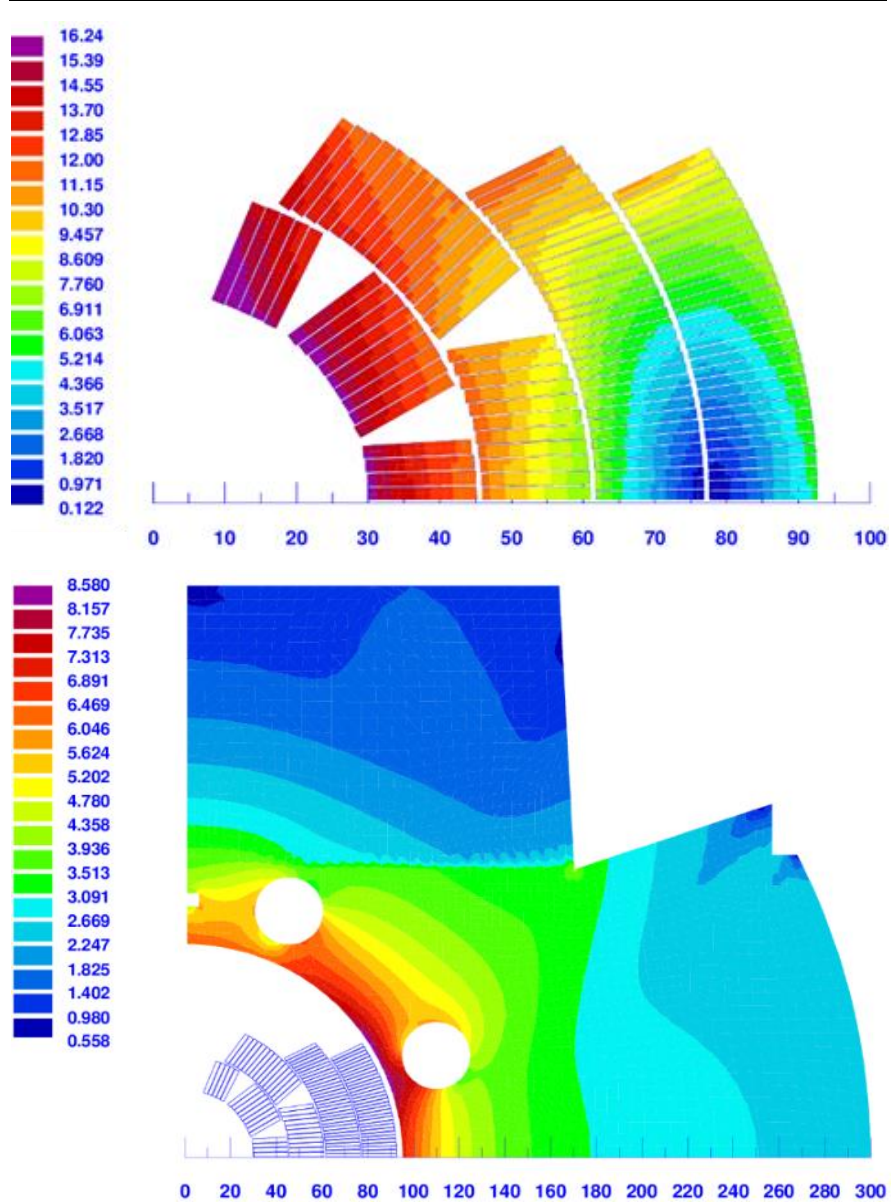

Fig. 3. 2D field distribution in the coil (top) and the iron yoke (bottom).

The geometrical harmonics in the magnet straight section at the reference radius of $17 \mathrm{~mm}$ are summarized in Table III.

TABLE III

NORMAL RELATIVE HARMONICS ( $10^{-4}$ OF THE DIPOLE COMPONENT)

\begin{tabular}{cc}
\hline \hline Harmonic & Value \\
\hline $\mathrm{b}_{3}$ & 0.0018 \\
$\mathrm{~b}_{5}$ & 0.0154 \\
$\mathrm{~b}_{7}$ & 0.0523 \\
$\mathrm{~b}_{9}$ & 0.0612 \\
\hline \hline
\end{tabular}


The calculated effects of superconductor magnetization and iron saturation on the "normal" relative sextupole field component $b_{3}$ as a function of dipole field in the magnet bore are shown in Fig. 4. The superconductor magnetization was calculated for a $\mathrm{Nb}_{3} \mathrm{Sn}$ sub-element diameter of $52 \mu \mathrm{m}$ in the two innermost layers (1 mm RRP-150/169 strand) and $41 \mu \mathrm{m}$ in the two outermost layers ( $0.7 \mathrm{~mm}$ RRP-108/127 strand). The iron saturation effect was calculated for an iron having $M_{s}$ of $2.14 \mathrm{~T}$.

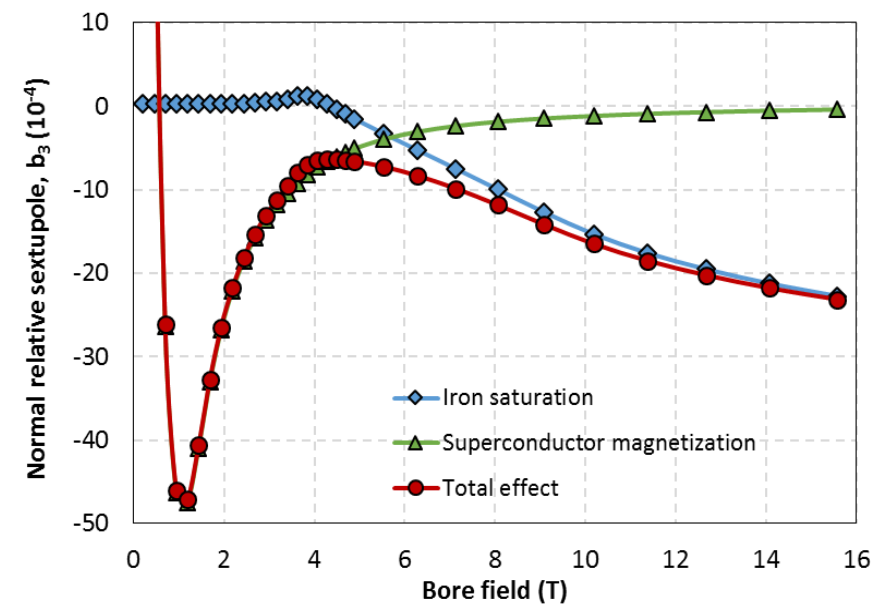

Fig. 4. Effects of superconductor magnetization and iron saturation on the normal relative sextupole $b_{3}$ during current ramp-up in the second excitation cycle.

Due to large coil volume, high $J_{c}$ and large $\mathrm{Nb}_{3} \mathrm{Sn}$ subelement size the superconductor magnetization effect in the normal sextupole component $b_{3}$ in the $15 \mathrm{~T}$ demonstrator is large. The absolute peak value of $b_{3}$ reaches $\sim 48$ units at a bore field of $\sim 1 \mathrm{~T}$. It is a factor of two larger than in the 2-layer $11 \mathrm{~T}$ dipole where it attains $\sim 20$ units [11], and an order of magnitude larger than in the NbTi LHC main dipoles. Since the iron yoke is close to the coil in the $15 \mathrm{~T}$ dipole demonstrator, the iron saturation effect is also large. The variation of the normal sextupole $b_{3}$ due to the iron saturation in the $15 \mathrm{~T}$ dipole demonstrator is more than 20 units.

No special field quality correction is envisioned for the first $15 \mathrm{~T}$ dipole demonstrator since it will be used to measure the unaltered, weakly-coupled coil magnetization and iron saturation effects, and to benchmark the computation codes. For future models, a persistent current corrector, similar to that developed for previous magnets [12], will be considered in conjunction with optimizing holes in the iron yoke - the techniques also previously used at Fermilab [13] to further suppress both non-linear effects.

The 3D magnetic analysis was performed using the OPERA 3D code. Fig. 5 shows the complete 4-layer coil and the coil end design. The length of both ends of the two outermost layers was minimized in order to increase the length of the magnet straight section. Small end spacers were used in these layers to split the large blocks and reduce the accumulated turn inclination. For mechanical reasons the iron yoke is extended over the coil ends. In that case, the peak field point limiting the magnet performance is in the coil ends. To reduce the field enhancement in the coil ends with respect to the magnet straight section, the pole blocks of the two innermost layers were shifted towards the magnet center.

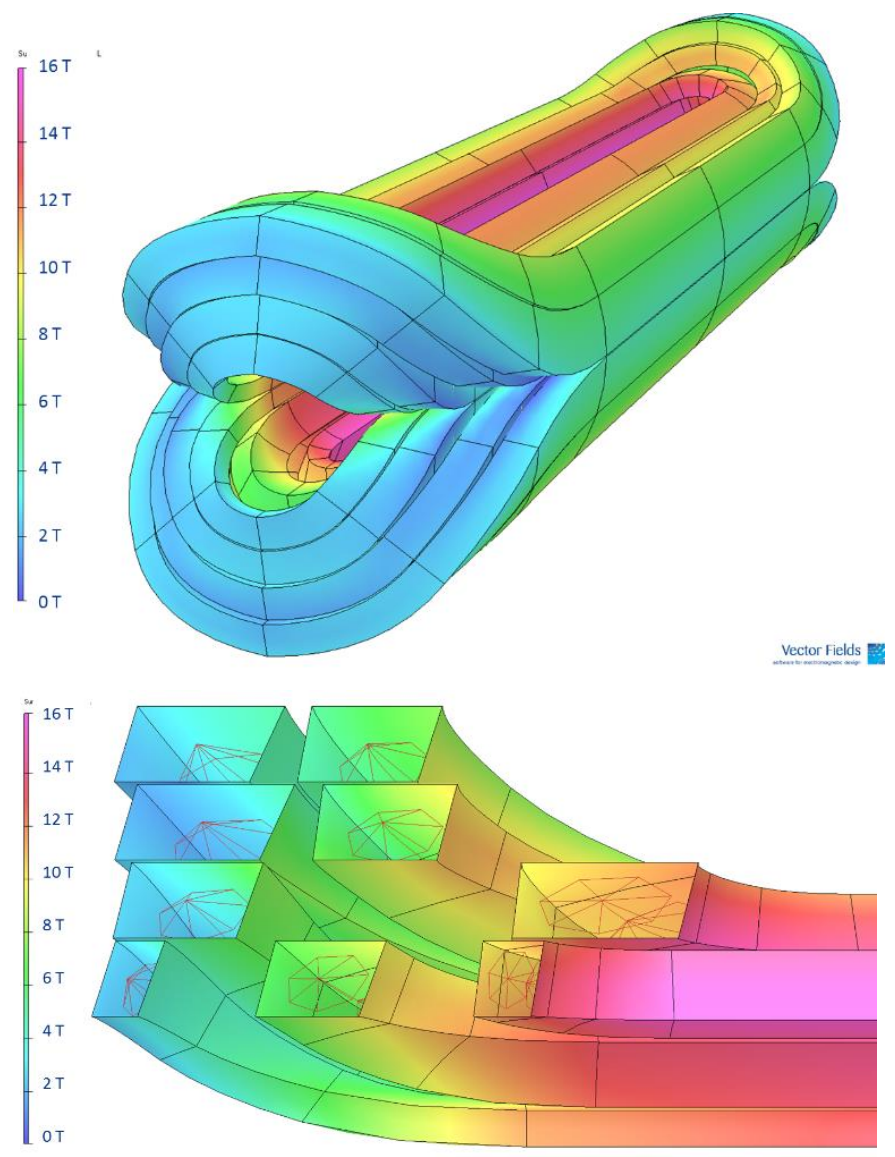

Fig. 5. Complete coil (top) and the coil end cross-section (bottom) with the magnetic flux distribution at the magnet short sample limit.

A cylindrical cut-out was also introduced in the ends of the iron yoke, as shown in Fig. 6, to reduce the peak field in the coil ends. There is a $2 \%$ field enhancement in the coil ends without the cutout. Removing $\sim 45 \mathrm{~mm}$ of the iron yoke material around the coil ends helps to reduce the peak field in the end to the same level as in the magnet central cross-section.

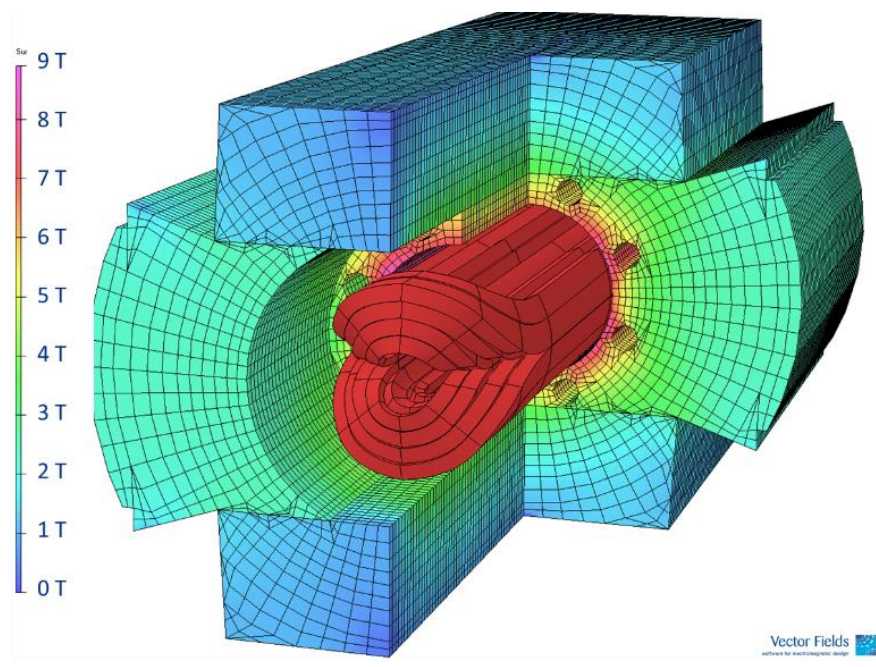

Fig. 6. 3D model with flux density in the iron yoke at the short sample limit. 
The coil cross-sections, optimized with ROXIE, were input into the BEND program [14] where the three-dimensional end geometry of each group was optimized by minimizing the strain energy in the cables with respect to "bend in the hard direction", providing also the information on turn twist and radius of curvature. Slight shifting and manual adjustments of the BEND parameters were done to produce a cable geometry that does not require bottom-supporting parts. The output files from BEND were then directly imported into a CAD package. The completed CAD geometry can then be imported into other programs for magnetic field and coupled mechanical and thermal FEA.

Fig. 7 shows the end geometry (top) and corresponding end parts (bottom) for both lead and return ends of the innermost coil layer. Fig. 8 shows the two outermost layers of the coil. The 2-layer inner coil uses Ti-alloy poles, bronze wedges and end spacers, and stainless steel saddles. All parts of the 2-layer outer coil are made of stainless steel.

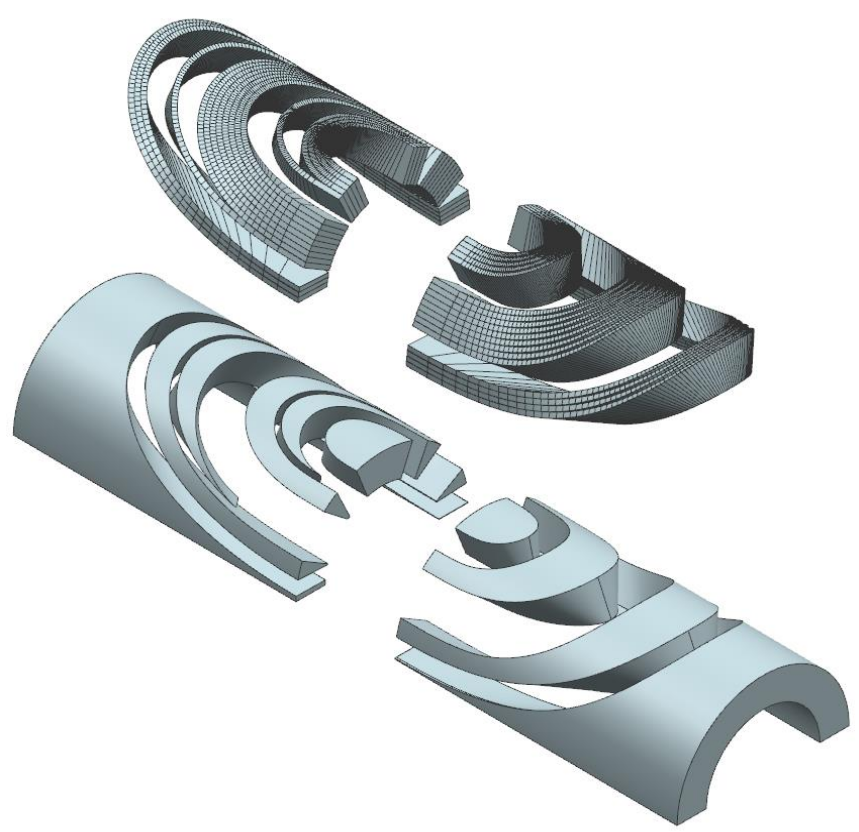

Fig. 7. The end geometry of the innermost coil layer (top) and corresponding end parts (bottom). The left and right sides of the Figure correspond to the lead ends and return ends respectively.

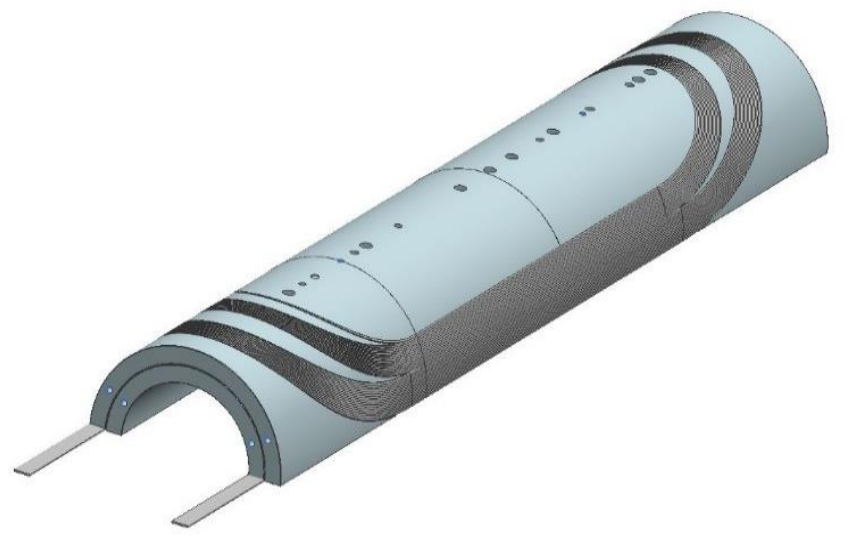

Fig. 8. The two outermost layers of the coil.

\section{STRUCTURAL ANALYSIS}

Finite element analysis using a parametric 2D ANSYS model was performed to optimize the stress in the coil and the main elements of the magnet support structure, and to minimize the conductor motion and magnet cross-section deformation at room and operation temperatures up to the design field of $15 \mathrm{~T}$.

The ANSYS model of the $15 \mathrm{~T}$ dipole demonstrator in two cross-sections is shown in Fig. 9. The baseline materials used in the magnet and their properties are listed in Table IV. The data for the $\mathrm{Nb}_{3} \mathrm{Sn}$ coil are based on measurements reported in [15]. The key criteria of the mechanical optimization were a) maintaining the coils under compression up to the design field of $15 \mathrm{~T}$, and $\mathrm{b}$ ) keeping the maximum coil stress below $\sim 180$ MPa during magnet assembly and operation.
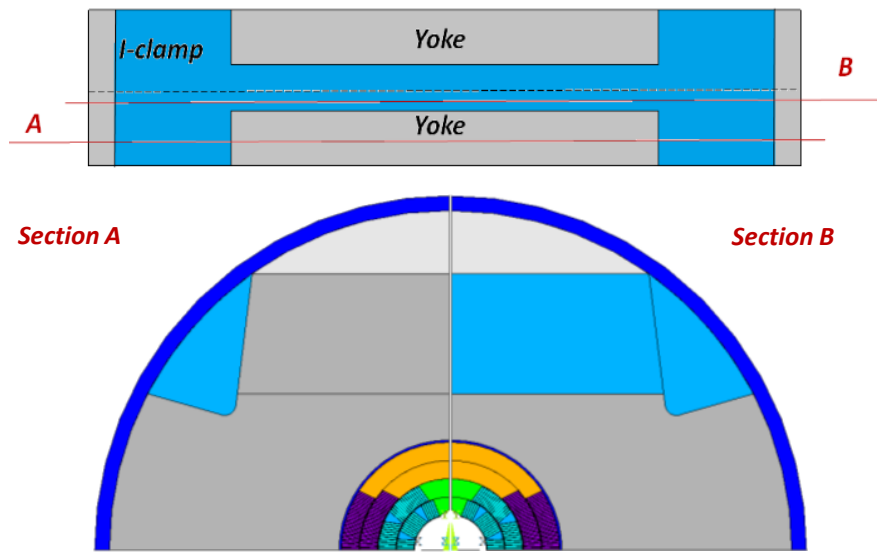

Fig. 9. ANSYS model of $15 \mathrm{~T}$ dipole (bottom) for section A (left) and section $B$ (right) shown on the top sketch.

TABLE IV

MATERIAL PROPERTIES.

\begin{tabular}{|c|c|c|c|c|c|c|}
\hline \multirow{2}{*}{$\begin{array}{l}\text { Structural } \\
\text { element }\end{array}$} & \multirow[t]{2}{*}{ Material } & \multirow{2}{*}{$\begin{array}{c}\text { Thermal } \\
\text { contract. } \\
(300-2 \mathrm{~K}) \text {, } \\
\mathrm{mm} / \mathrm{m}\end{array}$} & \multicolumn{2}{|c|}{$\begin{array}{c}\text { Elasticity } \\
\text { modulus, GPa }\end{array}$} & \multicolumn{2}{|c|}{$\begin{array}{c}\text { Yield stress, } \\
\mathrm{MPa}\end{array}$} \\
\hline & & & warm & cold & warm & cold \\
\hline Coil (rad/azim) & $\begin{array}{c}\mathrm{Nb}_{3} \mathrm{Sn} \\
\text { composite }\end{array}$ & $2.9 / 3.3$ & $35 / 20$ & $40 / 40$ & $\mathrm{n} / \mathrm{a}$ & $\mathrm{n} / \mathrm{a}$ \\
\hline Inn.coil pole blocks & Ti-6Al-4V & 1.7 & 115 & 125 & 650 & $>900$ \\
\hline Out.coil pole blocks & St Steel & 2.9 & 195 & 215 & 230 & 500 \\
\hline Wedges & Bronze & 3.2 & 110 & 120 & 280 & 350 \\
\hline Coil-yoke spacer & St Steel & 2.9 & 190 & 210 & 230 & 500 \\
\hline Clamp & Aluminum & 4.1 & 70 & 81 & 500 & 600 \\
\hline Yoke & Iron & 2.0 & 210 & 225 & 350 & $>400$ \\
\hline Skin & St Steel & 2.9 & 190 & 210 & 230 & 500 \\
\hline
\end{tabular}

Distributions of the equivalent stress in the coil after assembly, after cooling down and at $15 \mathrm{~T}$ bore field are shown in Fig. 10. The average transverse (azimuthal) stress in the pole and mid-plane turns of the coil layers at the above stages is summarized in Table $\mathrm{V}$. The maximum equivalent coil stress at room temperature and after cooling down is $\sim 110 \mathrm{MPa}$ and $\sim 150 \mathrm{MPa}$ respectively in the innermost-layer pole turn. The prestress increase in the pole-turns is achieved by providing the proper gap between the two halves of the iron yoke during assembly. The gap is closed after cooling down and stays closed up to $15 \mathrm{~T}$. At the bore field of $15 \mathrm{~T}$, the maximum equivalent coil stress is in the innermost layer mid-plane turns and is close to $178 \mathrm{MPa}$. 
1PoBA_04

http://dx.doi.org/10.1109/TASC.2016.2517024

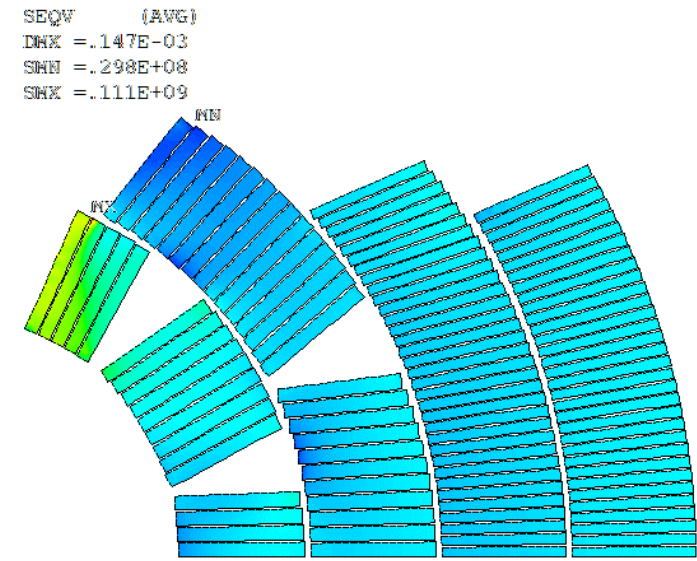

SEDW \{MWE\}

DAH $=.4464 E-03$

SNitid $=.560 \mathrm{E}+0 \mathrm{e}$

$\mathrm{SHXK}=.14 \mathrm{KE}+09$

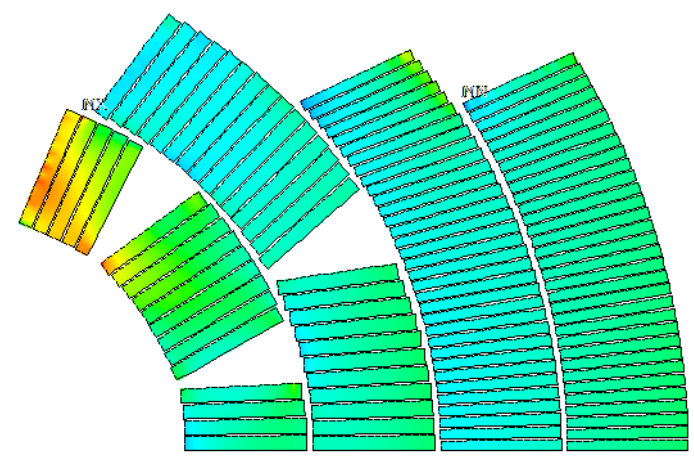

SEQ [सW

DNH $=.404 \mathrm{E}-03$

SNH $=.228 \mathrm{E}+07$

$\operatorname{SHHX}=.178 \mathrm{E}+09$
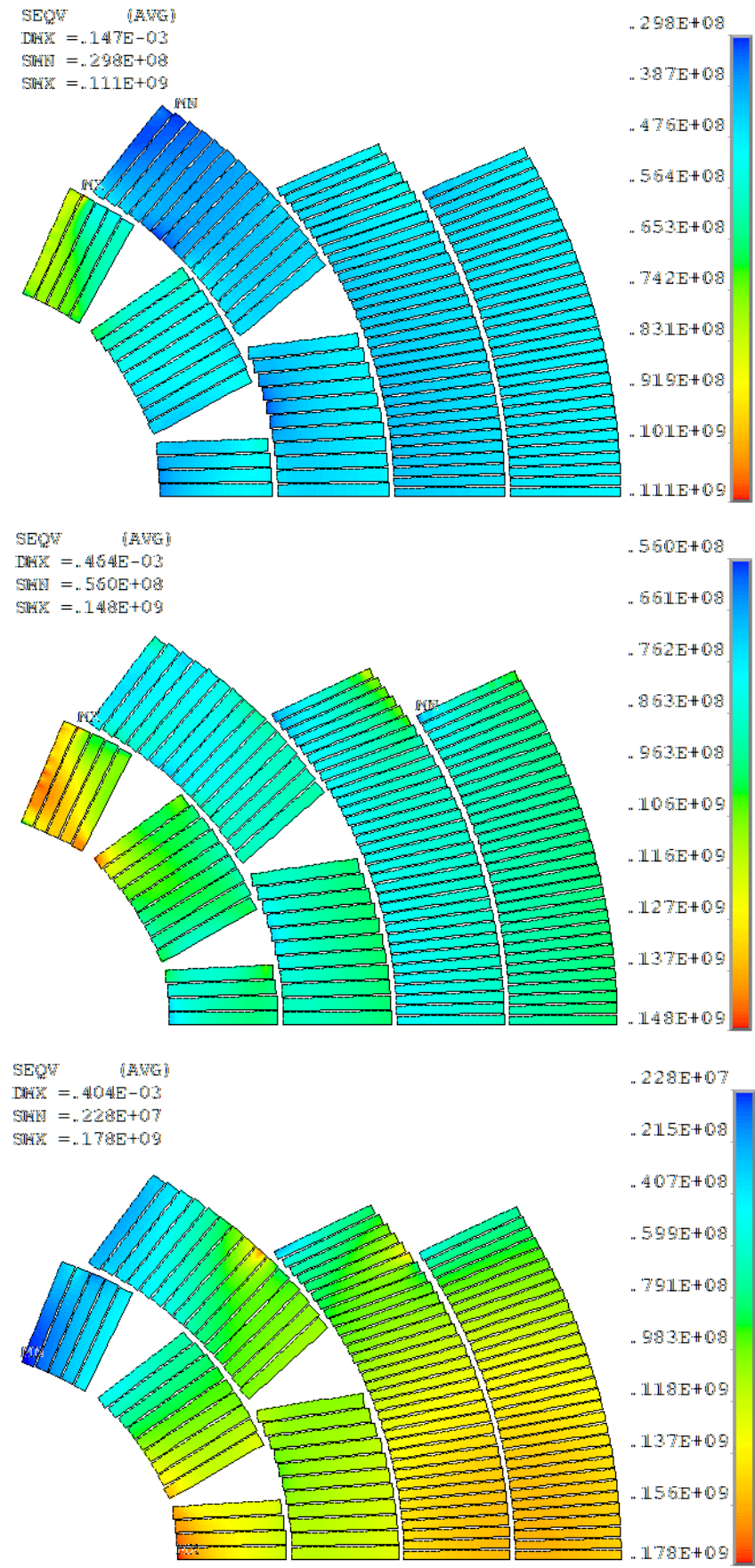

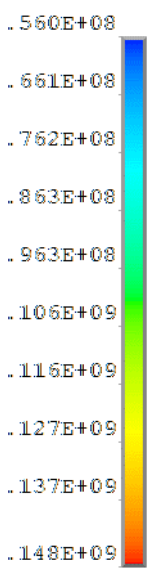

$228 \mathrm{E}+107$

$.21 .5 \mathrm{E}+108$

$.407 E+108$

$.599 \mathrm{E}+108$

. 791.E+108

. 983E+108

. $118 \mathrm{E}+109$

. 1137EHOQ

. $156 \mathrm{E}+109$

$178 E+109$

Fig. 10. Equivalent stress distribution in the coil at room temperature after assembly (top), after cooling down (middle) and at the $15 \mathrm{~T}$ bore field (bottom).

TABLE V

AVERAGE AZIMUTHAL STRESS IN SELECTED TURNS.

\begin{tabular}{lccc}
\hline \hline & \multicolumn{3}{c}{ Azimuthal coil stress, MPa } \\
\cline { 2 - 4 } Position in coil & Assembly & Cool down & B=15 T \\
\hline Pole 1 & 73 & 131 & 3 \\
Pole 2 & 36 & 82 & 24 \\
Pole 3 & 53 & 99 & 36 \\
Pole 4 & 51 & 100 & 66 \\
\hline Mid-plane 1 & 50 & 97 & 155 \\
Mid-plane 2 & 53 & 107 & 124 \\
Mid-plane 3 & 51 & 95 & 155 \\
Mid-plane 4 & 55 & 106 & 156 \\
\hline \hline
\end{tabular}
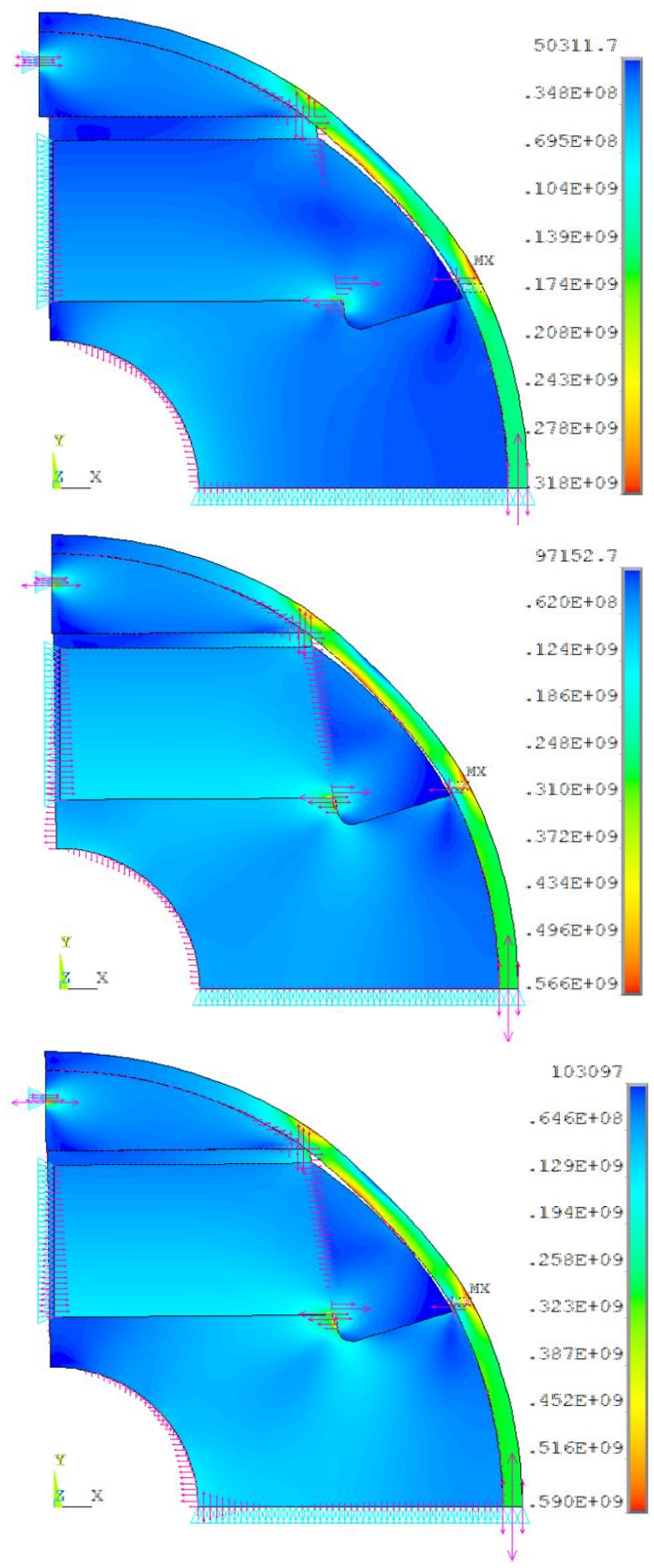

Fig. 11. Equivalent stress distribution in the support structure at room temperature after assembly (top), after cooling down (middle) and at $15 \mathrm{~T}$ bore field (bottom).

TABLE VI

MAXimum EQuivalent STReSS In Key STRUCTURAL ElEMENTS (MPA).

\begin{tabular}{lccc}
\hline \hline \multirow{2}{*}{$\begin{array}{l}\text { Structural } \\
\text { element }\end{array}$} & \multicolumn{3}{c}{ Maximum stress, MPa } \\
\cline { 2 - 4 } & Assembly & Cool down & $\mathrm{B}=15 \mathrm{~T}$ \\
\hline Yoke & 210 & 360 & 490 \\
Clamp & 205 & 430 & 450 \\
Skin & 318 & 566 & 590 \\
\hline \hline
\end{tabular}


Distributions of the equivalent stress in the dipole mechanical structure are shown in Fig. 11. The maximum values of the equivalent stress in the major elements of the magnet support structure, which were calculated at different assembly and operation stages, are presented in Table VI. All the results were obtained using a conservative model with elastic material properties. The stress level in clamps, iron laminations and skin during magnet assembly and operation are at an acceptable level for the materials used.

\section{CABLE OPTIMIZATION}

The 40-strand Rutherford cable used in the two outermost coil layers was developed and optimized for the $11 \mathrm{~T} \mathrm{LHC}$ dipole [9]. No additional optimization was needed for this cable. Three unit lengths of this cable with $0.7 \mathrm{~mm}$ diameter RRP-108/127 strands are presently available for the outer coils of the $15 \mathrm{~T}$ demonstrator dipole. A cross-section of the 40strand Rutherford cable is shown in Fig. 12 (top).

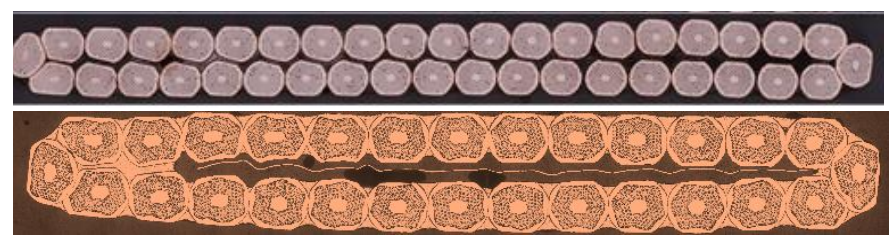

Fig. 12. Cross-sections of the 40-strand (top) and 28-strand (bottom) Rutherford cables.

The Rutherford cable with 28 strands of $1 \mathrm{~mm}$ diameter and $14.7 \mathrm{~mm}$ nominal width before reaction was optimized for the $15 \mathrm{~T}$ dipole demonstrator using state-of-the-art RRP ${ }^{\circledR}$ wires. A cross-section of the optimized 28-strand Rutherford cable is shown in Fig. 12 (bottom).

The cable samples were fabricated in one pass. They all included an $11 \mathrm{~mm}$ wide $0.025 \mathrm{~mm}$ thick stainless steel core to suppress eddy currents and obtain better field quality and ramp rate dependence in magnets. The first series of cable samples made of RRP-108/127 strands demonstrated critical current degradation smaller than $4 \%$ over the whole range of packing factors up to $92 \%$ encompassed by the cables [16]. Then cable degradation studies were continued with a RRP-150/169 wire most recently procured for the $15 \mathrm{~T}$ dipole demonstrator.

The critical current $I_{c}$ at $4.2 \mathrm{~K}$ normalized to the average $I_{c}$ of the virgin wires $(P F=78.5 \%)$ is plotted in Fig. 13 as a function of cable packing factor for two different external field values. The $I_{c}$ degradation was less than $3 \%$ for cables up to $\sim 90 \%$ cable compaction.

The Residual Resistivity Ratio $(R R R)$ was measured as the ratio of the wire resistivity at room temperature over its residual resistivity at $19.5 \mathrm{~K}$. Fig. 14 shows the $R R R$ as a function of $P F$ for the RRP-150/169 extracted strands. The overall $R R R$ of the wires decreased more or less linearly with compaction and was more than 250 up to $~ 90 \%$ cable compaction.

Based on these results, the nominal mid-thickness of the inner-coil unreacted cable that was chosen for the $15 \mathrm{~T}$ dipole is $1.80 \mathrm{~mm}$.

The $I_{c}(B)$ dependences, measured using extracted strands at $4.2 \mathrm{~K}$, and calculated for 4.5 and $1.9 \mathrm{~K}$ using parameterization [17] for the 28-strand cable, as well as the $15 \mathrm{~T}$ dipole demonstrator load lines (LL) are shown in Fig. 15. The magnet short sample limits estimated based on these data are $11.05 \mathrm{kA}$ $\left(\mathrm{B}_{0}=15.25 \mathrm{~T}\right)$ at $4.5 \mathrm{~K}$ and $12.2 \mathrm{kA}\left(\mathrm{B}_{0}=16.65 \mathrm{~T}\right)$ at $1.9 \mathrm{~K}$, which is consistent with the design parameters shown in Table II.

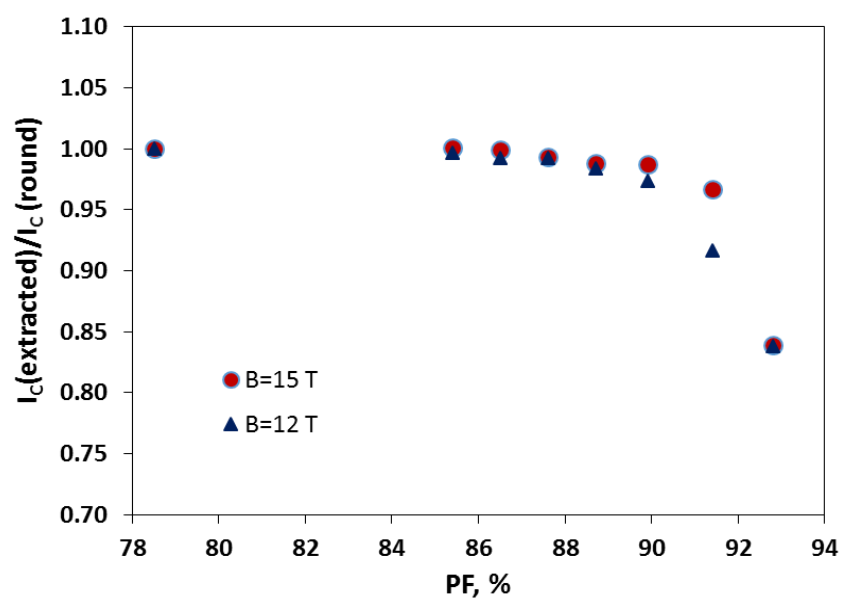

Fig. 13. Extracted strand $I_{c}$ at $4.2 \mathrm{~K}$ normalized to $I_{c}$ of virgin wire vs. cable packing factor for cables made with RRP-150/169 $\mathrm{Nb}_{3} \mathrm{Sn}$ strands.

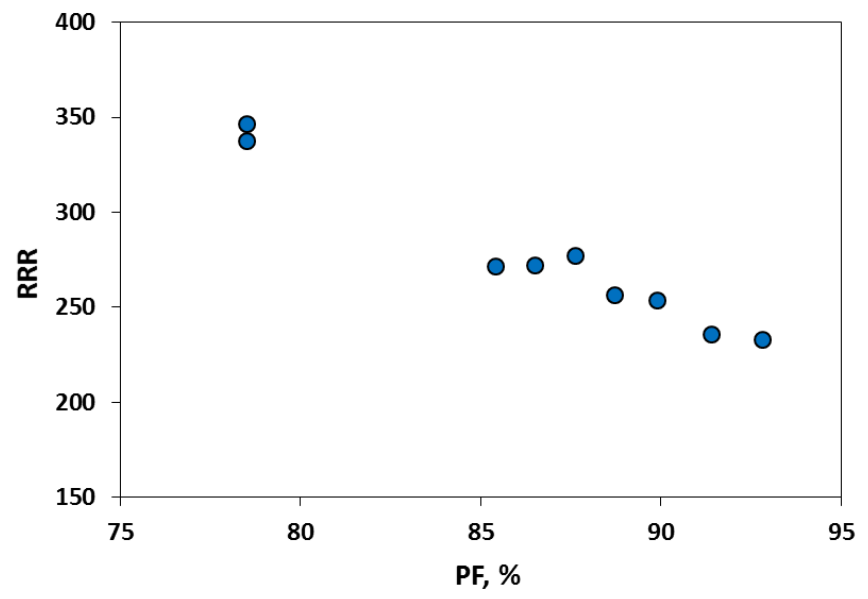

Fig. 14. $R R R$ as a function of cable packing factor for RRP-150/169 strands.

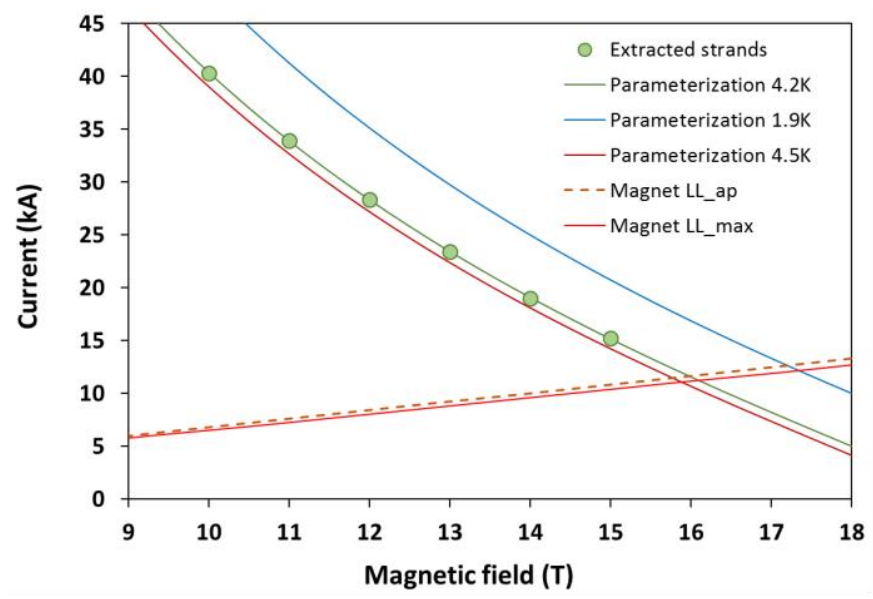

Fig. 15. Measured and parameterized $I_{c}(B)$ dependences for the 28 -strand cable and $15 \mathrm{~T}$ dipole demonstrator load lines (LL). The LL_ap and LL_max represent the magnetic field in the magnet aperture and the maximum field in the coil respectively as function of magnet current. 


\section{CONCLUSIONS}

A $15 \mathrm{~T} \mathrm{Nb}_{3} \mathrm{Sn}$ dipole demonstrator for a future $\mathrm{HC}$ is being developed at Fermilab. Magnet design is based on a 4-layer graded block cos-theta coil with $60 \mathrm{~mm}$ aperture and cold iron yoke. The magnet maximum field estimated based on the cable data is $15.25 \mathrm{~T}$ at $4.5 \mathrm{~K}$ and $16.65 \mathrm{~T}$ at $1.9 \mathrm{~K}$.

There are large non-linear superconductor magnetization and iron saturation effects in the sextupole field component. No special field quality correction is envisioned for the first $15 \mathrm{~T}$ dipole demonstrator. Tuning of the field quality using various techniques will be explored in future models.

The magnet support structure has been optimized to manage the large level of Lorentz forces. The concept has been radically changed from the previous iteration, which revealed excessively high stresses in the magnet structure and a possible separation of the pole turns at the maximum field. It was shown that the new structure allows keeping the stresses in the coil and support structure within acceptable limits during magnet assembly and operation.

Cable samples for both inner and outer coils were fabricated and tested. The cable packing factor was optimized to achieve a low degradation of cable critical current and copper matrix conductivity. The design of a 4-layer coil, including coil ends, mechanical structure and tooling is complete and being procured. Magnet fabrication and first test are planned for 2016.

\section{ACKNOWLEDGEMENT}

The authors thank the staff of Fermilab Technical Division for contributions to magnet and tooling design as well as cable fabrication and test.

\section{REFERENCES}

[1] "Building for Discovery: Strategic Plan for U.S. Particle Physics in the Global Context," P5 Report, http://science.energy.gov/ /media/hep/hepap/pdf/May\%202014/FINAL _P5_Report_053014.pdf

[2] Future Circular Collider Study Kickoff Meeting, Geneva, Switzerland, February 12-14, 2014, http://indico.cern.ch/event/282344/timetable/\#20140212

[3] CEPC/SppC study in China, http://indico.cern.ch/event/282344/session/1/contribution/65/material/sli des/1.pdf

[4] A.V. Zlobin et al., "Design concept and parameters of a $15 \mathrm{~T} \mathrm{Nb}_{3}$ Sn dipole demonstrator for a $100 \mathrm{TeV}$ hadron collider," Proc. of IPAC2015, Richmond (VA), May 2015.

[5] V.V. Kashikhin et at., "Magnetic and structural design of a $15 \mathrm{~T} \mathrm{Nb}_{3} \mathrm{Sn}$ accelerator dipole model," Proc. of CEC/ICMC2015, Tucson (AZ), 2015. IOP Conf. Ser.: Materials Science and Engineering (MSE), submitted for publication.

[6] A.V. Zlobin, "Status of $\mathrm{Nb}_{3} \mathrm{Sn}$ Accelerator Magnet R\&D at Fermilab", EuCARD - HE-LHC'10 AccNet mini-workshop on a "High-Energy LHC", 14-16 October 2010, FERMILAB-PUB-11-001-TD, CERN Yellow Report CERN-2011-003, p. 50 [arXiv:1108.1869].

[7] A.V. Zlobin et al., "11 T Twin-Aperture $\mathrm{Nb}_{3} \mathrm{Sn}$ Dipole Development for LHC Upgrades," IEEE Trans. Appl. Supercond., v. 25, Issue 3, June 2015, 4002209.

[8] ROXIE Code for an Electromagnetic Simulation and Optimization of Accelerator Magnets, http://cern.ch/roxie.

[9] N. Andreev et al., "Development of Rutherford-type Cables for High Field Accelerator Magnets at Fermilab," IEEE Trans. Appl. Supercond., v. 17, Issue 2, June 2007, p. 1027.

[10] E. Barzi et al., "Development and Fabrication of $\mathrm{Nb}_{3}$ Sn Rutherford Cable for the 11 T DS Dipole Demonstration Model," IEEE Trans. Appl. Supercond., v. 22, Issue 3, June 2012, 6000805.
[11] B. Auchmann et al., "Magnetic Analysis of a Single-Aperture 11T Nb $\mathrm{T}_{3} \mathrm{Sn}$ Demonstrator Dipole for LHC Upgrades", Proceedings of IPAC2012, New Orleans, Louisiana, USA, p. 3596.

[12] V.V. Kashikhin et al., "Passive Correction of the Persistent Current Effect in $\mathrm{Nb}_{3} \mathrm{Sn}$ Accelerator Magnets," IEEE Trans. Appl. Supercond. vol. 13, no. 2 , June 2003, p. 1270.

[13] G. Ambrosio et al., "Magnetic Design of the Fermilab $11 \mathrm{~T} \mathrm{Nb}_{3} \mathrm{Sn}$ Short Dipole Model," IEEE Trans. Appl. Supercond. vol. 10, no. 1, March 2000, p. 322.

[14] J. M. Cook, "Strain Energy Minimization in SSC Magnet Winding," IEEE Trans. on Magnetics, vol. 27, March 1991, p.1976.

[15] D. R. Chichili et al., "Investigation of Cable Insulation and ThermoMechanical Properties of Epoxy Impregnated $\mathrm{Nb}_{3} \mathrm{Sn}$ Composite," IEEE Trans. on Applied Supercond., vol. 10, no. 1, 2000, p. 1317.

[16] E. Barzi et al., " $\mathrm{Nb}_{3} \mathrm{Sn} \mathrm{RRP} \circledast$ Strand and Rutherford Cable development for 15 T Accelerator Magnets," this conference.

[17] L.T. Summers et al., "A model for the prediction of $\mathrm{Nb}_{3} \mathrm{Sn}$ critical current as a function of field, temperature, strain and radiation damage", IEEE Trans. on Magnetics, 27 (2): 2041-2044 (1991). 